\title{
A FUNÇÃO SOCIAL DO DIREITO DE PROPRIEDADE NO ESTADO CONTEMPORÂNEO
}

\author{
THE SOCIAL FUNCTION OF PROPERTY LAW IN THE CONTEMPORARY \\ STATE
}

\author{
Elizabeth Accioly Rodrigues da $\operatorname{Costa}^{1}$ \\ Francisco Cardozo Oliveira ${ }^{2}$
}

Flávia Jeane Ferrari ${ }^{3}$

\section{RESUMO}

O objetivo do presente artigo é compreender o direito de propriedade sob a ótica de sua função social e suas limitações. A temática justifica-se diante dos inúmeros prejuízos causados à sociedade e ao meio ambiente por iniciativas e ações advindas da propriedade privada, quando não observada a legislação vigente de maneira adequada. $\mathrm{O}$ trabalho desenvolve inicialmente um apanhado histórico com intuito de compreender a construção histórica do conceito de propriedade, discutindo posteriormente questões e normas relativas à função social da propriedade, além de tratar igualmente das limitações impostas pelo Estado ao direito de propriedade, com fim de preservar e garantir o equilíbrio entre o desenvolvimento e o bem estar social. Dessa maneira, o presente artigo desenvolveu uma pesquisa de abordagem qualitativa, de procedimento

1 Graduada em Direito pela Faculdade de Direito de Curitiba, Diplomada em Estudos Europeus pelo Instituto Europeu da Faculdade de Direito da Universidade de Lisboa (1996), Doutora em Direito pela Universidade de São Paulo (2003), área de concentração em Direito Internacional. Atualmente é Professora do Curso de Direito da Universidade Europeia de Lisboa e Professora do Programa de Mestrado em Direito do Centro Universitário de Curtiba - UNICURITIBA. Atua na área de Direito Internacional Público, Direito da Integração, com ênfase no estudo da integração latino-americana, Direito da União Europeia, Direito Internacional Económico e Contencioso da União.Exerce a advocacia em Portugal e no Brasil

2 Doutor em Direito pela Universidade Federal do Paraná (2001). Mestre em Direito pela Universidade Federal do Paraná (1998). Graduado em Direito pela Faculdade de Direito de Curitiba (1989). É Juiz de Direito - Tribunal de Justiça do Estado do Paraná. Professor da Escola da Magistratura do Estado do Paraná - EMAP. Professor Permanente do Programa de Mestrado em Direito Empresarial e Cidadania do UNICURITIBA. Fez estágio Pós-Doutoral na Universidade Federal de Santa Catarina - UFSC (20142015).

${ }^{3}$ Mestranda em Direito Empresarial e Cidadania pelo Unicuritiba (2019). Especializações nas áreas de Ministério Público \& Estado Democrático de Direito (2019); Direito Militar (2018); Processo Civil (2017); Direito Ambiental (2017); Direito do Trabalho (2013) e Bel. Direito pela Facear (2012). Integrante do Programa Institucional de Iniciação Científica - PCI junto ao Centro Universitário Curitiba - Unicuritiba, Linha de Pesquisa: Compliance (2019). Cal Membro da Comissão para Combate à Corrupção do LIONS Club Curitiba Batel. Experiência na área jurídica como Assessora de Magistrado, Escrevente Juramentada, Conciliadora, Juíza de Paz, Professora, Perita e Avaliadora nas áreas de Meio Ambiente e Imobiliária. Atualmente sou Adjunta da Seção de Sindicância, Processos Administrativos e IPM, da Assessoria de Apoio para Assuntos Jurídicos da $5^{\text {a }}$ Região Militar - $5^{\text {a }}$ Divisão de Exército. E-mail: flaviajeane.ferrari@hotmail.com. 
bibliográfico, com fim de analisar as pesquisas existentes no que se referem ao direito de propriedade, sua função social e limitações, com o intuito de alcançar os objetivos propostos previamente.

Palavras-chave: Direito de propriedade. Função social. Limitações ao direito de propriedade. Estado contemporâneo.

\begin{abstract}
The purpose of this article is to understand the right to property from the perspective of its social function and limitations. The theme is justified in view of the countless losses caused to society and the environment by initiatives and actions arising from private property, when the current legislation is not properly observed. The work initially develops a historical overview in order to understand the historical construction of the concept of property, later discussing issues and norms related to the social function of property, in addition to addressing also the limitations imposed by the State on property rights, in order to preserve and ensure the balance between development and social welfare. In this way, the present article developed a qualitative research, using a bibliographic procedure, in order to analyze the existing research regarding the right to property, its social function and limitations, in order to achieve the objectives previously proposed.
\end{abstract}

keywords: Property right. Social role. Limitations on property rights. Contemporary state.

\title{
1 INTRODUÇÃO
}

$\mathrm{O}$ reconhecimento do direito de propriedade remonta à antiguidade, sendo retratado em praticamente todos os registros de normativas conhecidos. Com tal reconhecimento, também foram sendo percebidas certos abusos de poder por parte de quem detinha a propriedade (ANDERSON, 2001).

Com isso, fez-se necessário o estabelecimento de limitações a esse direito de propriedade, de modo que houvesse solidariedade e respeito entre o gozo do direito e a proteção aos direitos dos outros, sem acarretar prejuízos ao coletivo em detrimento do privado (SALES, 2010).

Com o estado contemporâneo, a compreensão da propriedade tomou novas dimensões, passando de um direito de cunho mais individualista para um direito de dimensão coletiva. Ou seja, ao direito de propriedade passou a ser atribuída a função social. Essa última tem por principal fim determinar medidas e estabelecer ações que contribuam para ajustar os interesses privados aos interesses e ao bem coletivo (BOBBIO, 2006). 
Mesmo assim, são incontáveis os prejuízos causados à sociedade por iniciativas e ações advindas da propriedade privada, quando não observadas a legislação vigente. Tais prejuízos vão desde danos materiais, no âmbito individual, até comprometimento de recursos naturais, bens da comunidade e patrimônio - de interesse coletivo da sociedade.

Assim, justifica-se levantar discussões acerca dos meios legais existentes no que tange às limitações adequadas ao direito de propriedade, bem como sua função social no que diz respeito à busca do bem comum social.

Dessa maneira, o objetivo geral do presente trabalho foi compreender o direito de propriedade sob a ótica de sua função social e suas limitações. Também se pretendeu, como objetivos específicos: fazer um apanhado histórico da concepção do direito de propriedade; entender o direito de propriedade como função social; entender as limitações impostas ao direito de propriedade, especialmente no meio urbano; discutir os prejuízos que podem ser ocasionados ao interesse coletivo pelo direito de propriedade exercido indevidamente.

O presente trabalho foi desenvolvido através da pesquisa de abordagem qualitativa, de procedimento bibliográfico. Logo, considerou-se artigos de periódicos, livros e normativas relacionadas à temática do direito de propriedade, sem que houvesse quantificação de valores ou dados específicos. 


\section{ORIGENS E EVOLUÇÃO HISTÓRICA DO DIREITO DE PROPRIEDADE}

Existem diversas controvérsias acerca dos fundamentos, origem e natureza do conceito de propriedade. Há correntes que defendem que a propriedade se trata de uma idealização do próprio Estado, logo, que segue as determinações e regulamentos deste sobre suas bases.

Por outro lado, há teóricos que defendem a propriedade como sendo um direito natural, ou seja, pertencente a um conjunto de direitos cujas origens são anteriores a quaisquer convenções humanas ou leis de cunho civil e que determinam os preceitos básicos das relações humanas desde tempos remotos (DÉRATHÉ, 2009).

Essa última corrente também diz respeito a uma interpretação mais primitiva do próprio ser humano. Pois, nesse viés, a propriedade deriva do instinto de sobrevivência, que ditava ao indivíduo a necessidade de tomar em sua posse suprimentos, bens e territórios como forma de atender às suas primordialidades, como a alimentação e o abrigo, por exemplo (RIOS, 2014).

Para abordar a respeito da origem histórica da propriedade, é preciso remeter aos primórdios da humanidade. Nesse período, de acordo com Costa (1977), a propriedade tinha uma natureza coletiva, quer dizer, os grupos humanos em sua maioria viviam no nomadismo, $\log$ o bens de propriedade imóvel não eram tão substanciais quanto instrumentos de subsistência e autodefesa, por exemplo.

Fora a propriedade dos bens móveis (seja individual ou coletiva), o autor não descarta a existência de ditas ideias de propriedade advindas do caráter místico e religioso das crenças das pessoas da época, atribuindo tais aspectos a locais sagrados ou importantes para esses povos.

Mesmo assim, ao tratar estritamente da propriedade imóvel, remete-se a um estilo de subsistência diferente do nomadismo, caracterizando, portanto, o estabelecimento de grupos e comunidades em territórios delimitados.

Essa delimitação, não sendo natural, advém da apropriação de determinado local por pessoas ou um indivíduo, que passa a referir-se a este como o seu lugar, mesmo que tal local não pertencesse necessariamente a ninguém anteriormente (ROUSSEAU, 1989). 
Em contrariedade com o direito natural, outros teóricos, com o passar do tempo, foram tratando a ideia de propriedade como um direito instituído somente a partir do Estado, vista como uma concessão do mesmo, uma vez que, afora das atribuições do Estado, existe apenas posse (BOBBIO, 2016).

Nesse contexto, de acordo com Campos Junior (2002), foi Samuel Pufendorf que estabeleceu a diferenciação entre o chamado direito natural e o direito positivo, sendo este último fundado justamente sob premissas da concepção de propriedade.

Assim, de acordo com Sahd (2013, p. 59): “embora a justiça seja definida pelo direito natural, ela só é possível sob o direito positivo".

Desse modo, os fundamentos das constituições montam-se sobre os direitos naturais, embora suas garantia e salvaguardas sejam garantidas pelo direito positivo, por meio do Estado.

\subsection{O Direito de Propriedade: primeiros registros}

A questão da propriedade individual, privada, surgem argumentos e dispositivos de proteção dessa propriedade que remetem à Antiguidade Clássica, inclusive alguns presentes no Código de Hamurabi (ANDERSON, 2001).

Seguindo nesse contexto, Gonçalves (1955, p. 181) chama a atenção para outras questões relacionadas à propriedade privada desde seus primórdios:

\footnotetext{
A história documentada dos mais antigos povos do mundo não nos revela a existência de tal comunismo primitivo da terra. Pelo contrário, o que por toda parte se verifica, na Ásia, na África e na Europa antigas e que a propriedade da terra não era concedida a todos os entes humanos; Em cada país eram delas excluídos os estrangeiros, os escravos e os membros da família, as mulheres e filhos que eram eles próprios objeto da propriedade do chefe ou pater família (GONÇALVES, 1955, p. 181).
}

Logo nota-se também outra característica da propriedade privada em suas origens: a consideração e o privilégio da cidadania, devido ao temor de possíveis invasões das cidades e comunidades por pessoas e povos estrangeiros (ZAKKA, 2007). 
Por outro viés, também havia o caráter religioso e divino relacionado à concepção de propriedade. Na Grécia antiga, por exemplo, a propriedade tinha uma natureza sagrada e não era assegurada por uma instituição civil, mas sim por crenças religiosas aceitas naquele meio (BLANC, 2004).

Isso era comum principalmente em se tratando de terras familiares, que eram passadas para os descendentes dos mortos, além da edificação de altares na terra, tornando-a uma propriedade daquele grupo, tomando por fundamento a alma daqueles indivíduos que ali foram ligadas à terra através de enterros e edificações religiosas (BLANC, 2004).

\subsection{O Direito de Propriedade no Império Romano}

No período do Direito Romano, a propriedade também era vista, de acordo com Anderson (2001), como uma questão privada, atribuída aos chefes familiares (pater família). Nesse caso, os demais membros da família, como filhos e as mulheres, bem como os bens materiais, todos estes, eram considerados parte da propriedade do chefe da família. Ou seja, filhos e mulheres eram banidos da propriedade, sendo esta de exclusividade apenas do pater família.

Mesmo assim, foi no Direito Romano, ainda durante o período clássico, que passam a surgir algumas limitações à propriedade privada, limitações estas impostas pelo Estado. Nesse sentido, Maluf (1997) cita alguns exemplos dessas limitações do período, entre elas:

[...] nas províncias, a propriedade - quer mobiliária, quer imobiliária - é sujeita a uma série de limitações impostas no interesse da administração pública; assim, por exemplo, os móveis (alimentos, animais, veículos) podem ser requisitados pelo Estado, e os imóveis estão sujeitos ao ônus de alojar tropas (MALUF, 1997, p. 15).

Desde então, já no período pós-clássico (compreendido no Direito, como do século III d.C. ao século VI d.C.), essas limitações foram se tornando mais expressivas, tomando maiores dimensões no âmbito urbano (considerando limites entre vizinhos) e no 
que diz respeito à ordem pública, limitações essas impostas e determinadas pelo Estado (SALES, 2010).

Segundo o autor Alves (1969), discute e traz limitações ainda mais extensas acrescidas à propriedade privada no período pós-clássico do Direito, além de outras criadas a partir de então:

a) enquanto, no período clássico, as minas pertencem ao proprietário do terreno, onde se encontram, no pós-clássico ele está obrigado a admitir escavações feitas por estranhos, cabendo-lhe um décimo do produto obtido (igual proporção é devida ao Estado);

b) aumentam as limitações no que diz respeito a construções nas cidades (por exemplo: uma não pode distar da outra menos de 12 pés; e de 15 , se se tratar de edifício público: 100 pés é a altura máxima dos edifícios);

c) no direito Justiniano, a matéria relativa a águas que correm do terreno superior para o inferior sofre modificações, proíbe-se que o proprietário do imóvel superior faça construções que impeçam, além dos limites de sua necessidade de água, que ela flua para o terreno inferior, ou que se utilize da água em medida superior à das necessidades do imóvel;

d) o proprietário que não cultiva seu terreno perde a propriedade sobre ele em favor de quem o cultivou por mais de dois anos;

e) por motivos de ordem pública ou privada, surgem várias normas que impedem que se alienem certas coisas;

f) o proprietário de um imóvel não pode levantar construção que impeça que o vento atinja o terreno vizinho (ALVES, 1969, p. 316-317).

Visto dessa forma, o direito primitivo romano de propriedade passa a atribuir a si mesmo um caráter não só de direito privado, mas também inclui aspectos da moral e obrigações do proprietário para com os ideais e necessidades públicas. Ou seja, a propriedade privada é um direito, com tanto que respeitadas as limitações e normas que regem esse direito.

\subsection{O Direito de Propriedade no período Medieval}

Após a queda do império romano e o advento da Idade Média, a partir do século V, a propriedade passou a ser associada, segundo Anderson (2001), ainda mais 
intrinsicamente com a questão de poder, riquezas e dominações do povo mais pobre através do sistema feudal.

O regime dos feudos medievais desse período realçou ainda mais as desigualdades sociais entre os grandes proprietários de terra (nobreza) e seus vassalos que apenas cultivavam as terras dos senhores, mediante pagamento de valores, impostos, produção e de lealdade (ANDERSON, 2001).

A respeito dos interesses da nobreza nesse sistema feudal de Zakka (2007, p. 33) explica:

Segundo os historiadores, em troca de proteção contra invasões, a alta nobreza, composta pelos antigos proprietários, confiava o domínio eminente de suas terras ao soberano, jurando-lhe fidelidade, subordinação pessoal e prestação de serviços. Em troca recebia o benefício, que, em regra, era a preservação da titularidade do domínio útil sobre os feudos, bem como o poder político, consubstanciado pelo direito de comandar, punir, aplicar a justiça e cobrar impostos sobre a população local (ZAKKA, 2007, p. 33).

Dessa maneira, existia uma situação de fragmentação do direito de propriedade no período medieval. Esse sistema, portanto, viabilizava condições de total dependência entre os nobres e reis, grandes proprietários, e os seus servos e vassalos, os quais estavam nas últimas escalas da hierarquia de poder na época.

Esse sistema da época tornou-se, portanto, um método de ampla dominação da população mais pobre e desprovida de propriedades, perpetuando assim o sistema que favorecia apenas uma seleta parcela de pessoas (ANDERSON, 2001).

\subsection{O Direito de Propriedade no Estado Moderno}

Posteriormente ao período medieval, de acordo com Zakka (2007), surgiu uma nova linha de centralização do poder no âmbito Estatal, centralização esta distinta dos poderes fragmentados existentes até então, onde cada senhor das terras tinha suas próprias normas e aplicava a justiça a partir de métodos próprios. Logo, a centralização desse poder passou a viabilizar também negociação de propriedades imóveis (como as terras, até então de posso exclusiva dos senhores). 
Isso também garantiu certa liberdade e igualdade entre os indivíduos perante o Estado. Não que isso fosse atendido à rigor na realidade, porém a lei passou a ser o único fundamento a partir do qual o Estado poderia atuar e cumprir suas normas (ANDERSON, 2001).

Nesse momento de uma sociedade mais liberal, segundo Villey (2005), a normalização vigente passou a garantir também direitos fundamentais intrínsecos ao indivíduo, inclusive à livre iniciativa - e o direito à propriedade. Isso fomentou a circulação de bens, inicialmente em forma de trocas e, posteriormente, através de um comércio mais estruturado.

Com isso, o Estado Moderno e suas legislações passaram a garantir uma igualdade de direitos entre os indivíduos, fato que, como já destacado, não garante a igualdade de bens materiais, apenas direitos formalizados (ANDERSON, 2001). Prova disso foi a classe burguesa e seu enriquecimento após o crescimento das indústrias.

Assim, a partir do século XVI a fragmentação do poder medieval passou a dar lugar a um poder mais centralizado, ditado por normas gerais e um Estado liberal já com um caráter capitalista (VILLEY, 2005).

Logo, com o crescimento da burguesia, crescia também o descontentamento do proletariado com as condições de trabalho e de subsistência. Assim em 1789 inicia a Revolução Francesa, a partir da qual nasceu a Declaração dos Direitos do Homem e do Cidadão, no mesmo ano (VILLEY, 2005).

A partir de então, o direito de propriedade passa a ter um caráter inviolável, sendo garantido pelo Estado. A alienação deste direito só ocorreria em casos extraordinários. Tais casos seriam de interesse do Estado, mesmo nesse caso de privação ao direito de propriedade, haviam processos indenizatórios ao proprietário (ZAKKA, 2007).

Dessa forma, o estado liberal foi suplantado pelo moderno devido novamente às relações desiguais entre burguesia e proletariado, bem como as relações de trabalho cada vez mais conflituosas e exploratórias. O estado moderno é instalado então com o ideal de possibilitar uma atenção mais correta às classes sociais desfavorecidas, através da distribuição de renda, bem como o alinhamento os interesses nas relações trabalhistas (VILLEY, 2005). 


\section{A FUNÇÃO SOCIAL DA PROPRIEDADE}

A partir do século XX passa-se a entender o direito de propriedade sobre uma ótica oposta ao individualismo anterior do direito moderno. A ótica do direito contemporâneo. Surge a partir daí a chamada positivação dos direitos, ou seja, passa-se a discutir então a função social da propriedade (BOBBIO, 2006).

Nesse momento, a propriedade deixa de ser compreendida exclusivamente sob a ótica do direito. Quer dizer, diversos autores começaram a cultivar a teoria da propriedade enquanto função social, um meio de atender e auxiliar as necessidades do interesse público social (RIOS, 2014).

No âmbito nacional brasileiro, a propriedade poder ser entendida a partir de dois vieses principais. O primeiro deles tem um caráter mais individualista - no Código Civil de 2002. E a propriedade na Constituição Federal, vista nessa última a partir de uma atribuição de funcionalidade social à propriedade.

A Constituição da República Federativa do Brasil, já no seu artigo $1^{\circ}$ enaltece como um de seus principais intuitos a construção de um meio nacional e uma sociedade fundada sobre o princípio da solidariedade. Logo, tal objetivo não pode ser alcançado facilmente apenas através de ações advindas do Estado.

E a propriedade, ao perder seu caráter mais individualista, tendendo para a necessidade de atender também às necessidades sociais, abrange-se também para o setor empresarial. Esse aspecto limita possíveis ações de cunho abusivo do direito da propriedade por parte de empresários proprietários e seus agregados.

Quanto a isso, Salomão Filho (2004, p. 2) explica:

Estendida à empresa, a ideia da função social da empresa é uma das noções de talvez mais relevante influência prática na transformação do direito empresarial brasileiro. É o princípio norteador a regulação externa dos interesses envolvidos pela grande empresa. Sua influência pode ser sentida em campos tão dispares como direito antitruste, direito do consumidor e direito ambiental (SALOMÃO FILHO, 2004, p. 2). 
Assim, há de ser associar as ações constitucionais ao interesse privado, estabelecendo normas e exigências que cooperem no desenvolvimento de ações para o coletivo, que possam, de alguma maneira trazer benefícios mútuos à sociedade como um todo.

A respeito das relações de propriedade, sua função social e demais aspectos, a Constituição Federal, em seu artigo 170, determina:

Art. 170. A ordem econômica, fundada na valorização do trabalho humano e na livre iniciativa, tem por fim assegurar a todos existência digna, conforme os ditames da justiça social, observados os seguintes princípios:

I - soberania nacional;

II - propriedade privada;

III - função social da propriedade;

IV - livre concorrência;

$\mathrm{V}$ - defesa do consumidor;

VI - defesa do meio ambiente, inclusive mediante tratamento diferenciado conforme o impacto ambiental dos produtos e serviços e de seus processos de elaboração e prestação;

VII - redução das desigualdades regionais e sociais;

VIII - busca do pleno emprego;

IX - tratamento favorecido para as empresas de pequeno porte constituídas sob as leis brasileiras e que tenham sua sede e administração no País (BRASIL, 1988).

Trata-se de tornar o meio social mais digno, que preze pelo respeito à vida e ao meio ambiente através da solidariedade e da busca de um bem comum. Ou seja, uma empresa ou indústria que possua propriedades, sejam imóveis ou bens monetários não pode agir de maneira indiscriminada e irresponsável com a comunidade ao seu redor causando prejuízos aos mesmos, nem atentar contra o meio ambiente em seu entorno durante suas atividades (CARDOSO; SANJUAN, 2017).

Dessa maneira, ainda de acordo com Cardoso e Sanjuan (2017), o setor empresarial deve ter e responder pela responsabilidade social e ambiental em suas atividades e a respeito de seu direito de propriedade.

Logo cabe a todos, ainda que em sua individualidade, trabalhar com ações que viabilizem a justiça social em todas as suas esferas. Evitando assim a supervalorização da propriedade individualista que contribui com a deficiência na distribuição de renda e para o aumento da desigualdade social (BAUMAN (2001). 
Pois, visto o que determina o artigo 170, da Constituição Federal, toda propriedade deve estar atrelada à uma função social definida, caso contrário a mesma sofre sansões e até punições por parte do Estado, o que ao fim limita sua atuação e existência (BRASIL, 1988).

Isso porque no Estado Contemporâneo, a propriedade deixa de ser vista como algo individualizado e inatingível. A propriedade tem sua segurança e garantias asseguradas pelo Estado enquanto a mesma contribui com o meio social.

No Estado atual, tendo em vista os princípios constitucionais, a propriedade privada deve se colocar e agir em favor do setor coletivo, e não somente de si próprio. Ora, a propriedade, enquanto imersa na sociedade e usufruindo dos recursos de toda espécie deverá por si também contribuir com o crescimento e melhorias sociais e ambientais.

\section{LIMITAÇÕES AO DIREITO DE PROPRIEDADE}

Portanto, vê-se que as normalizações do Estado, inclusive a Constituição Federal de 1988, bem como o Código Civil de 2002 estabelece uma série de limitações à propriedade e às suas atuações.

Nesse sentido, o Código Civil, Lei $\mathrm{n}^{\circ}$ 10.406, de 10 de janeiro de 2002 em seu artigo 1.228, determina algumas limitações ao direito de propriedade no Brasil:

Art. 1.228. O proprietário tem a faculdade de usar, gozar e dispor da coisa, e o direito de reavê-la do poder de quem quer que injustamente a possua ou detenha.

§ $1 \mathrm{O}$ direito de propriedade deve ser exercido em consonância com as suas finalidades econômicas e sociais e de modo que sejam preservados, de conformidade com o estabelecido em lei especial, a flora, a fauna, as belezas naturais, o equilíbrio ecológico e o patrimônio histórico e artístico, bem como evitada a poluição do ar e das águas.

$\S 2$ São defesos os atos que não trazem ao proprietário qualquer comodidade, ou utilidade, e sejam animados pela intenção de prejudicar outrem.

§ 3 O proprietário pode ser privado da coisa, nos casos de desapropriação, por necessidade ou utilidade pública ou interesse social, bem como no de requisição, em caso de perigo público iminente.

§ 4 O proprietário também pode ser privado da coisa se o imóvel reivindicado consistir em extensa área, na posse ininterrupta e de boa-fé, por mais de cinco anos, de considerável número de pessoas, e estas nela houverem realizado, em 
conjunto ou separadamente, obras e serviços considerados pelo juiz de interesse social e econômico relevante.

$\S 5$ No caso do parágrafo antecedente, o juiz fixará a justa indenização devida ao proprietário; pago o preço, valerá a sentença como título para o registro do imóvel em nome dos possuidores (BRASIL, 2002).

Visto através do Código Civil Brasileiro, o direito de propriedade novamente é delimitado por meio de seu bom uso, em prol do bem comum, não de um caráter egoísta. Isso é salientado pelo $\S 2^{\circ}$, que esclarece a contrariedade da norma a casos de abuso do direito de propriedade.

Tais abusos podem ser os mais diversos possíveis, sendo sempre relacionados a práticas egoístas, individualistas e que tem por fim causar danos e prejuízos a terceiros. Para o autor Sales (2010, p. 44) exemplifica que tais casos podem ser "a construção realizada por um vizinho com o fito exclusivo de irritar o outro, ou, ainda, o proprietário que ateia fogo em sua plantação".

Tais casos configuram um uso indevido da propriedade e, além disso, não traz benefícios ao proprietário e são realizados apenas com intuito de prejudicar os demais por razões infundadas.

Isso contraria os preceitos da legislação no sentido de que nesta, a propriedade não é mais entendida como apenas posse, mas como um instrumento para contribuir com a construção de uma sociedade solidária.

$\mathrm{O} \S 1^{\circ}$, por sua vez traz à tona alguns dos aspectos mais fundamentais a serem considerados quanto ao direito de propriedade. Quanto à propriedade, o Código Civil deixa claro a primazia pelo bem coletivo sobre os interesses individuais. Isso advém do entendimento de que proprietários seja de imóveis, bens ou empresas tem um poder maior de atuação (e dano) sobre os interesses coletivos, logo a eles são atribuídas maiores responsabilidades.

O referido inciso garante o gozo do direito de propriedade contanto que sejam atendidas as normas vigentes acerca da natureza, dos recursos naturais, da fauna e flora. Esse é um aspecto que claramente remete à preocupação pelo bem comum.

Ora, se, por exemplo, uma indústria instalada próxima a uma determinada comunidade passa a descartar resíduos poluentes e nas águas do rio mais próximo, lançar 
poluentes nocivos ao ar e desmatar florestas locais, tais ações imediatamente começariam a causar danos à vida das pessoas que residem naquela comunidade.

Caso não houvessem sanções do Estado sobre tais atos e a indústria não tivesse ética social em suas atividades, a comunidade pereceria, enquanto a indústria continuaria a lucrar diante de ações irresponsáveis, em detrimento do lucro.

Quanto ao Patrimônio Histórico e Artístico, da mesma maneira, a legislação busca proteger a memória, edifícios, sítios e artefatos históricos de ações irresponsáveis da propriedade privada, através determinações de leis mais específicas ao assunto.

Nesse âmbito, as limitações e a função social da propriedade estendem-se principalmente ao meio urbano. Em seu artigo 182, a Constituição Federal esclarece:

Art. 182. A política de desenvolvimento urbano, executada pelo poder público municipal, conforme diretrizes gerais fixadas em lei, tem por objetivo ordenar o pleno desenvolvimento das funções sociais da cidade e garantir o bem-estar de seus habitantes.

$\S 1^{\circ} \mathrm{O}$ plano diretor, aprovado pela Câmara Municipal, obrigatório para cidades com mais de vinte mil habitantes, é o instrumento básico da política de desenvolvimento e de expansão urbana.

$\S 2^{\circ} \mathrm{A}$ propriedade urbana cumpre sua função social quando atende às exigências fundamentais de ordenação da cidade expressas no plano diretor (BRASIL, 1988).

A política urbana determinada no artigo 182 trata da propriedade no meio urbano, garantido a ela pleno desenvolvimento, enquanto observadas as exigências para a mesma, determinadas pelo plano diretor da cidade.

Esse plano diretor trata-se de um mecanismo que orienta e estabelece os princípios para a ocupação do terreno urbano, tendo por base os interesses de cunho coletivo e difuso, prezando pelos aspectos já resumidos no $\S 1$, do artigo 1.228, da Constituição Federal - além de outros. O plano diretor é obrigatório para cidades com mais de vinte mil habitantes e é de responsabilidade do município (BLANC, 2004). 
Assim, a propriedade no meio urbano permanece com suas limitações, bem como suas obrigações quanto à função social, de modo a viabilizar ao ambiente urbano um crescimento sustentável, justo e solidário, sem prejuízos a outrem (SALES, 2010).

É importante, por fim, delimitar a diferença entre a limitação e a função social da propriedade enquanto direito. Quanto à limitação, Sales (2010, p. 47):

\begin{abstract}
As limitações do direito de propriedade são exigências impostas pelo ordenamento jurídico a fim de adequar o uso do bem pelo proprietário aos interesses da sociedade, por exemplo, respeitar o conteúdo do direito de vizinhança, das diretrizes administrativas, do direito ambiental, urbanístico etc. (SALES, 2010, p. 47)
\end{abstract}

Já quanto à função social do direito de propriedade, Sales (2010, p. 47) finaliza explicando que a mesma "visa a estimular o uso da coisa, compatibilizando os interesses individuais aos coletivos". 


\section{PROCEDIMENTOS METODOLÓGICOS}

O presente trabalho foi desenvolvido através da pesquisa de abordagem qualitativa, de procedimento bibliográfico. Dessa maneira, foram realizados pesquisas e estudos acerca do direito de propriedade, seu histórico e definições com o intuito de compreender a importância deste direito na sociedade atual, bem como investigar a existência de desigualdades sociais derivadas da propriedade enquanto direito.

A pesquisa desenvolvida, bem como as conclusões às quais chegou-se foram alcançadas sem que houvesse quantificação de valores ou dados específicos (GERHARDT, SILVEIRA, 2009).

Para o procedimento de pesquisa, foram considerados artigos de periódicos e revistas especializados em Direito de Propriedade, principalmente os publicados nos últimos anos, bem como teses e dissertações, além de livros da área e pertinentes à temática abordada. 


\section{CONSIDERAÇÕES FINAIS}

Tendo em vista que o objetivo geral do presente trabalho foi compreender o direito de propriedade sob a ótica de sua função social e suas limitações, pode-se definir, primeiramente, a construção histórica desse direito, desde os primórdios da humanidade, até suas abrangências e limitações no estado contemporâneo.

$\mathrm{Na}$ atualidade, é evidente no cotidiano a supervalorização dos interesses de grandes proprietários em detrimento de pessoas e comunidades sem propriedades de abrangência considerável.

Em consequência, nota-se o crescimento da desigualdade social, o prejuízo causado por grandes indústrias aos recursos naturais, às pequenas propriedades e aos bens de indivíduos das classes menos favorecidas.

Essas ações, muitas vezes veladas por estados, governos e municípios perpetua situações de desigualdade social, de pobreza, de insuficiência na distribuição de renda, na moradia, na educação, favelização, saneamento básico, entre outras consequências graves à sociedade.

Nesse sentido, é imprescindível a discussão da função social do direito de propriedade, enquanto meio de equilibrar e tornar justos os interesses da propriedade e do coletivo. Esse aspecto é de fundamental importância para tornar a propriedade um meio de melhora e desenvolvimento social, junto ao Estado.

Conclui-se, portanto, que ao Estado cabe, além de estimular ações de interesse social por parte da propriedade privada, como também estabelecer e executar sanções quando as limitações estabelecidas ao direito de propriedade não forem observadas.

Com ações nesse sentido, é possível tornar a coexistência do coletivo e do privado algo menos danoso ao bem comum, contribuindo para a construção de uma sociedade mais solidária e responsável. 


\section{REFERÊNCIAS}

ALVES, José Carlos Moreira. Direito Romano. 2. ed. Rio de Janeiro: BORSOI, 1969.

ANDERSON, Perry. Passagens da Antiguidade ao Feudalismo. São Paulo: Editora Brasiliense, 2001.

BAUMAN, Zygmunt. Modernidade Líquida. Rio de Janeiro: Jorge Zahar Editor, 2001.

BLANC, Priscila Ferreira. Plano diretor urbano e função social da propriedade. Jurua Editora, 2004.

BOBBIO, Norberto. Jusnaturalismo e positivismo jurídico. São Paulo: Editora Unesp, 2016.

BOBBIO, Norberto. O positivismo jurídico: lições de filosofia do direito. Ícone, 2006.

BONAVIDES, Paulo. Teoria do Estado. Rio de Janeiro: Editora Forense, 1980.

BRASIL. Lei n. 10.406, 10 de janeiro de 2002. Institui o Código Civil. Diário Oficial da União, Brasília, 2002. Disponível em: http://www.planalto.gov.br/ccivil_03/Leis/2002/L10406compilada.htm. Acesso em: 10 fev. 2020.

BRASIL. Constituição da República Federativa do Brasil. Brasília: Senado Federal, Centro Gráfico, 1988.

CAMPOS JUNIOR, Raimundo Alves de. O conflito entre o direito de propriedade e o meio ambiente e a questão da indenização das áreas de preservação florestal. 2002. Dissertação (Mestrado). Programa de Pós-Graduação em Direito, Universidade Federal de Pernambuco, Recife, 2002.

CARDOSO, Henrique Ribeiro; SANJUAN, Pedro Ernesto Celestino Pascoal. A relação entre a função socioambiental da propriedade e os direitos humanos - o pagamento por serviços ambientais (PSA). Revista Jurídica, v. 2, n. 47, p. 277-296, 2017.

COSTA, Jose Rubens. Síntese histórica da propriedade imóvel. Revista Forense, 1977.

DÉRATHÉ, Robert. Rousseau e a ciência política de seu tempo. Tradução de Natália Maruyama. São Paulo: Editoras Barcarolla e Discurso Editorial, 2009.

GERHARDT, Tatiana Engel; SILVEIRA, Denise Tolfo. Métodos de pesquisa. Plageder, 2009.

GONÇALVES, Luiz da Cunha. Tratado de Direito Civil. 2. ed. São Paulo: Max Limonad. 1955,

MALUF, Carlos Alberto Dabus. Limitações ao direito de propriedade. São Paulo: Saraiva, 1997 
RIOS, Thiago Menezes. Direito de propriedade, função social e limitações constitucionais. Jus Navigandi, 2014. Disponível em: https://jus.com.br/artigos/27032/direito-de-propriedade-funcao-social-e-limitacoesconstitucionais/1. Acesso em: 10 fev. 2020.

ROUSSEAU, Jean-Jacques. Discurso sobre a origem e os fundamentos da desigualdade entre os homens. Brasília: UnB, 1989.

SAHD, Luiz Felipe Netto de Andrade Silva. Samuel Pufendorf e a diferença entre Direitos Perfeitos e Imperfeitos. Pensando-Revista de Filosofia, v. 3, n. 6, p. 49-63, 2013.

SALES, Camila Bottaro. Humanização dos direitos reais: limitações do direito de propriedade aos novos direitos reais de uso e moradia. Dissertação (Mestrado em Direito) - Pontifícia Universidade Católica de Minas Gerais, Belo Horizonte, 2010.

SALOMÃO FILHO, Calixto. Função social do contrato: primeiras anotações. Revista dos Tribunais, v. 93, 2004.

VILLEY, Michel. A formação do pensamento jurídico moderno. São Paulo: Martins Fontes, 2005.

ZAKKA, Rogério Marcus. O direito de propriedade:(análise sob a ótica de sua convivência com a função social). 2007. Tese (Mestrado m Direito das Relações Sociais) - Pontifícia Universidade Católica de São Paulo, São Paulo, 2007.

WOLOCHN, Regina Fátima. A função social da propriedade e o Artigo 1276 do Código Civil de 2002. Revista Juridica, [S.1.], v. 1, n. 34, p. 270-288, fev. 2014. ISSN 2316-753X. <http://revista.unicuritiba.edu.br/index.php/RevJur/article/view/795/608>. Acesso em: 17 abr. 2020. doi:http://dx.doi.org/10.21902/revistajur.2316-753X.v1i34.795. 